\title{
Strategies for Dealing with Cultural Differences in the Translation of English Literature
}

\author{
Hongyan Guan
}

Xi'an University, Xi'an Shaanxi, 710065, China

Keywords: English Literature, Cultural Translation, Differences.

\begin{abstract}
There is a great cultural difference between Chinese culture and Western culture, which makes it necessary to completely eliminate this cultural difference that exists in the course of translating English literary works. Only in this way can we translate higher quality English literatures. Therefore, when translating English literary works, we must apply reasonable strategies to carry out translation work. This article explores the necessity of properly handling the cultural differences in English literary translation, analyzes the causes of cultural differences in English literary translation, and puts forward the main handling strategies for cultural differences in English literary translation.
\end{abstract}

\section{Introduction}

As one of the most important components of literary translation, the translation of English literary works is the transformation of linguistic forms, which means translating English literary works into Chinese literary works, is a cross-cultural and cross-temporal communication form of cultural exchanges and have a very important value. Translation is a language into another language, the purpose of translation is to create a more close to the original language works, not only to be able to fully demonstrate the original style and content, but also should be satisfied with the readers reading the text The cultural factors have a very important value in the translation of English literature. Therefore, the translator should understand in detail the cultural differences among different ethnic groups so as to be able to eliminate the cultural differences between the two languages when translating and achieve the goal of accurate translation.

\section{Necessity of Proper Handling of Cultural Differences in English Literary Translation}

Translating English literary works is a very complex process, in which Chinese and English are culturally different. If we fail to pay close attention to the differences between the two cultures when translating English literature, it will be extremely unfavorable to the accurate translation of English literature and will in turn affect the actual effectiveness of English literary translation. On the other hand, only when translating English literary works pays close attention to the differences between the two cultures, and according to the differences in the translating process, can we translate English literature more effectively. Therefore, whether is it possible to deal with the linguistic and cultural differences in the translation of English literary works by using accurate translation means in translation, which has a very important meaning for the improvement of translation quality of English literary works. Only by accurately grasping the differences between the two cultures in translation and properly handling the translation problems caused by cultural differences can literary works translate into accuracy. Cultural factors are precisely the factors that must be considered in the translation of English literary works. In the process of translation, if only translation is implemented in the form of language literal translation, even if there are no serious problems in translation, ignorance of the differences between the two cultures will make it difficult for people to understand them accurately. In this way, not only should the reader fully understand the content translated in the translation, but more importantly, the meaning of the differentiated cultural elements resulting from the language should be thoroughly understood. This requires a major breakthrough in cultural barriers, to be able to translate outstanding literary works. 


\section{Causes of Cultural Differences in English Literary Translation}

Language and culture are closely related. Language is the support of culture, while culture is the product of human thought and consciousness, but the soul of national language. Because of cultural differences, it is very important for translation practice. Before the implementation of the translator, the translator must carefully read the original text, not only to understand the surface meaning of the work, but also need to further grasp the original meaning of the profound cultural meanings, in particular, to grasp the original involved in both Chinese and English Cultural differences in cognition. In translating, we should not only pay attention to the conversion of both Chinese and English languages, but also need to pay more attention to the cultural similarities and differences between the two peoples in China and Britain. The causes of the differences are mainly the following two points: First, the historical and cultural differences. Due to the historical and cultural differences between Chinese and English languages, the translator can find some of the translations difficult to use corresponding language to replace them. For example, there has been various controversies for the title translation of the famous American novel The Gift of the Magi. The complex of the "Magi" is "magus," which comes from the Bible and is considered the inventor of the Christmas gift, the Three Wise Men of the East, to come before the birth of Jesus and to bring gold and myrrh as the gift. As far as religious culture is concerned, "Magi" is used to refer to sacrificial staff in Zoroastrianism. Della and her husband, the heroine in the novel, carefully prepare each other's Christmas gifts for each other. What the writer emphasizes is not a substantive gift, but the most sacred love between the couple, so take this as the title. However, for the average Chinese reader, the vast majority of people have not read the Bible and naturally do not understand the allusions. It is impossible to understand the implication of the word. Therefore, it is more in line with the cultural awareness of Chinese readers to translate The Gift of the Magi into 麦琪的礼物(mài qí dí lǐ wù). Second, the differences in customs. The so-called customs, mainly refers to the people in the corresponding geographical range of life style and behavior. Language and customs are closely related. For example, the word "red" means the color "red". In some English-speaking countries, because of its historically popular bullfighting culture in which the cloth used for bullfighting is red, red means the same color of blood, that dangerous and other undesirable cultural tendencies. In the Chinese language, red is often used to express the very positive cultural meaning of festivals and enthusiasm. For example, the traditional red dress of a Chinese wedding means happiness. In another example, according to Chinese customs, funerals must be dressed in white costumes, while a very lively suona or music implies that the deceased can board the world of eternity as early as possible, but Westerners believe that white is a symbol of purity and nobility, so people are often accustomed to wearing white wedding dresses, while funerals are wearing black suits.

\section{Main Strategies For Handling Differences in Cultural Translation in English Literature}

\subsection{Accurately understand literary genres to deal with cultural differences}

Differentiated genres have differentiated writing features and language features, these are all in the translation of English literature must take into account. Accurately distinguishing and recognizing the genre of English literature is an important basis for carrying out a good translation work. The differences in theme represent the differences in cultural factors. There are also differences in content and translation skills that must be taken into account in the process of translation, Different genres of works, can accurately show the style of the current works, so as to protect the quality of translation. Among the various works of English literature, commonly used genres include novels, essays and poems. The cultural factors covered by different genres of literary genres are different. For the novels, essays and poems, the above works have very profound cultural meanings and are very artistic. When translators need to translate these works, Pay more attention to the above factors, to understand the current culture, society and history, can reasonably contain the contents of the work to be expressed, the translator in the attention of these works, the work should first deal with the context of the emergence of such Factors are analyzed comprehensively, but also an overall comparison between 
the cultural background and the Chinese environment should be conducted to find out the differences and translate them in a reasonable language. At the same time, attention should also be paid to the habits of readers. Their works should not only express their meanings in the original language, but also be easy to read. However, there are differences in the methods and key points in the translation of scientific and technological works. Because science and technology articles tend to objectively describe a phenomenon and contain very few or even negligible cultural factors, literary translation should be implemented in literary translation. It is only necessary to ensure that the technical terms are accurate and too concerned about cultural factors while cannot translate excellent literary works. So in translating English literature, we must pay attention to the important meaning of the genre and thus have a very important value in translating high quality works.

\subsection{Introducing dynamic equivalences to address the differences between cultures}

When translating English literature, the full text should be fully translated, so that the contents of the article can be presented in detail to the readers, the original English content can be fully expressed in Chinese only, and the meaning represented in English Use Chinese expressions to achieve. However, it should also be noted that there are many differences between the English and Chinese languages, especially in the cultural field. In the course of implementing full-scale translation, not only should we fully understand the differences between the two cultures, but also deal with the cultural differences among themselves in the form of dynamic equivalence in translation. Equivalence translation, on the other hand, In the original text of the various types of words or phrases to be translated in order to come to its equivalent of the Chinese expression of meaning, and in the specific translation of English literature, the sole application of rigid forms of reciprocal translation and reciprocal translation of the translation of those translation Out of the meaning there may be a great deviation, and the consequences of translation is not accurate enough. The meaning of dynamic equivalence translation is that the implementation of translation can not only implement the equivalent translation of words, but also the implementation of the equivalent of grammatical translation. Of course, in the translation process, its genre characteristics also need to correspond to each other. The above problems should be fully considered in the translation process, so that translated works can fully maintain the original meaning and style.

\subsection{Use creative translation methods to deal with cultural differences}

When translating English literary works from time to time, we encounter problems that make us feel confused, that is, during translation, whether the translator is fully translated according to the meaning of the original text or whether the original text should be the premise, creatively integrate into your own understanding. In specific translation, because of genre differences, the strategy of solving the problem should also be different. It is all right for science and technology articles to fully incorporate their own understanding in translation, without any re-creation. Faithfulness in the original texts only needs to be accurately translated, but in the translation of poems, novels and essays In the need for separate study. As the above genre of English literature itself is re-creation of the English language, once the translation is only a simple copy of the translation can be, then the meaning and thoughts revealed in the article will be difficult for readers to understand. At the same time, translated articles naturally make people feel dull and boring. Precisely because of this cultural difference, translators are required to translate creatively and rebelliously in the process of translation, so as to be faithful to the original text and yet further higher than the original article so as to effectively translate the creative pole High work.

\subsection{Use the link between domestication and foreignization translation to deal with the differences between Chinese and western cultures}

When translating English literary works, quite a few ideas are usually applied, while alienated translations and home-based translations have a much higher utilization rate. Alienation here refers to the fact that English texts are kept to the utmost extent in English translation in order to better localize the original texts. Quite apart from the forms of alienated translation, domestication translation tends to focus on translation-oriented, that is, from the cultural background of literary works as the end 
result, and more about whether the translation can be understood by readers. The use of naturalized translation, the reader easier to understand. Regardless of the type of translation, respect must be given to the western cultural backgrounds exposed in the original works and the rational translation tendency should be chosen. However, this can not change the contents of the ideas put forward by the authors and translate the more readable works. For example, in the translation of Mr. Mao Dun's work "Shaken", alienation translation tools are used, so that the rich cultural connotation contained in the original text can be fully preserved. In the process of translating English literary works, the two types of translation should belong to the opposite translation modes. The focus of the domestication translation mode is to translate the solid cultural features of the works. Using the methods of domestication and foreignization to study cultural differences So as to better deal with the differences between Chinese and Western cultures so as to continuously improve the accuracy and quality of translation so as to fully demonstrate the richness and charm contained in the works.

\section{Conclusions}

To sum up, there are considerable cultural differences between different nations and countries. Therefore, when translating English literary works, we should attach great importance to the considerable differences between Eastern and Western cultures, which need to be dealt with accurately. In the process of translating English literary works, it is necessary to implement effective naturalization and alienation so as to effectively improve the effectiveness of cultural differences. Based on the actual cultural differences and readers' specific acceptance of different cultures, and alienation. From a general perspective, we can improve the actual quality of English literary translation through the combination of domestication and foreignization. Therefore, to grasp the differences between the translations means to promote the mutual contrast between Eastern and Western cultures, so that we can solve the problems that arise in the translation of English literature and thus improve the effectiveness of cultural differences in English literature.

\section{References}

[1] Wu Qiong. On How to Correctly Handle Cultural Differences in English Literary Translation, Journal of Liaoning Teachers College(Social Science Edition), 2014(6).

[2] Liu Guo. On How to Correctly Handle Cultural Differences in English Literary Translation, Guangdong Science, 2014(14).

[3] Tan Yin. How to Handle Chinese and Western Cultural Differences in the Translation of English Literary Works, English Square (academic research), 2014(2).

[4] Xin Yanyan. Differences between Chinese and Western Cultures Based on English Literary Translation, Journal of Ezhou University, 2015(5).

[5] Zheng Min. Cultural Differences in English Literary Translation, Intelligence, 2016(35). 